\title{
A time-lapse photography method for monitoring salmon (Oncorhynchus spp.) passage and abundance in streams
}

William W Deacy, William B Leacock, Lisa A Eby, Jack A Stanford

Accurately estimating population sizes is often a critical component of fisheries research and management. Although there is a growing appreciation of the importance of smallscale salmon population dynamics to the stability of salmon stock-complexes, our understanding of these populations is constrained by a lack of efficient and cost-effective monitoring tools for streams. Weirs are expensive, labor intensive, and can disrupt natural fish movements. While conventional video systems avoid some of these shortcomings, they are expensive and require excessive amounts of labor to review footage for data collection. Here, we present a novel method for quantifying salmon in small streams $(<15 \mathrm{~m}$ wide, $<1 \mathrm{~m}$ deep) that uses both time-lapse photography and video in a modelbased double sampling scheme. This method produces an escapement estimate nearly as accurate as a video-only approach, but with substantially less labor, money, and effort. It requires servicing only every 14 days, detects salmon $24 \mathrm{hrs}$. /day, is inexpensive, and produces escapement estimates with confidence intervals. In addition to escapement estimation, we present a method for estimating in-stream salmon abundance across time, data needed by researchers interested in predator-prey interactions or nutrient subsidies. We combined daily salmon passage estimates with stream specific estimates of daily mortality developed using previously published data. To demonstrate proof of concept for these methods, we present results from two streams in southwest Kodiak Island, Alaska in which high densities of sockeye salmon spawn. 
Title: A time-lapse photography method for monitoring salmon (Oncorhynchus spp.) passage and abundance in streams

William W. Deacy ${ }^{1}$, William B. Leacock ${ }^{2}$, Lisa A. Eby ${ }^{3}$, Jack A. Stanford ${ }^{1}$

${ }^{1}$ Flathead Lake Biological Station, University of Montana, Polson, MT, USA

${ }^{2}$ Kodiak National Wildlife Refuge, Kodiak, AK, USA

${ }^{3}$ Wildlife Biology Program, University of Montana, Missoula, MT, USA

Corresponding Author:

William Deacy

PO Box 9236, Missoula, MT, 59807, USA

Email address: will.deacy@gmail.com 


\section{Abstract}

2 Accurately estimating population sizes is often a critical component of fisheries research and

3 management. Although there is a growing appreciation of the importance of small-scale salmon

4 population dynamics to the stability of salmon stock-complexes, our understanding of these

5 populations is constrained by a lack of efficient and cost-effective monitoring tools for streams.

6 Weirs are expensive, labor intensive, and can disrupt natural fish movements. While

7 conventional video systems avoid some of these shortcomings, they are expensive and require

8 excessive amounts of labor to review footage for data collection. Here, we present a novel

9 method for quantifying salmon in small streams $(<15 \mathrm{~m}$ wide, $<1 \mathrm{~m}$ deep) that uses both time-

10 lapse photography and video in a model-based double sampling scheme. This method produces

11 an escapement estimate nearly as accurate as a video-only approach, but with substantially less

12 labor, money, and effort. It requires servicing only every 14 days, detects salmon $24 \mathrm{hrs}$. /day, is

13 inexpensive, and produces escapement estimates with confidence intervals. In addition to

14 escapement estimation, we present a method for estimating in stream salmon abundance across

15 time, data needed by researchers interested in predator-prey interactions or nutrient subsidies.

16 We combined daily salmon passage estimates with stream specific estimates of daily mortality

17 developed using previously published data. To demonstrate proof of concept for these methods,

18 we present results from two streams in southwest Kodiak Island, Alaska in which high densities

19 of sockeye salmon spawn.

\section{Introduction}

21 The management, research, and conservation of salmonids requires accurate estimations of

22 population sizes. Managers use salmon (Oncorhynchus spp.) escapement estimates (salmon 
23 remaining after harvest that enter freshwater to spawn) to develop stock-recruit curves and to

24 improve management timing of fisheries. Researchers often need escapement data for studies

25 involving productivity, nutrient subsidies, and predator-prey dynamics. Although we have good

26 escapement data for many main-stem rivers used by migrating salmon, we have little escapement

27 data at smaller scales, including small streams where many salmon ultimately spawn

28 (Anadromous Waters Catalog, Alaska Department of Fish and Game). This is regrettable given

29 that large salmon stock-complexes are composed of dozens or hundreds of distinct salmon

30 populations, many of which spawn in first and second order streams (Hilborn et al. 2003).

31 Collections of small salmon populations spawning at different times and in different locations

32 tend to have more stable interannual abundance than a single homogenous population due to

33 "portfolio effects," which results in more reliable returns and fewer closures for commercial

34 fisheries (Schindler et al. 2010). This stability arises from population diversity occurring at

35 small spatial scales (i.e. first and second order streams), hence the importance of having the tools

36 to investigate and understand these populations to effectively manage salmon for human and

37 wildlife consumers.

Watershed-scale escapement estimates do not effectively characterize the resources

available to wildlife consumers, because they do not tell us how long salmon are available to consumers. In many watersheds, consumers cannot catch salmon while they migrate up the

41 relatively deep water of main-stem rivers; they must wait until salmon enter shallow spawning

42 streams where they are more easily caught. As a result, consumers interact with individual

43 salmon populations rather than entire stock complexes, and thus, watershed scale escapement can

44 be a poor estimate of the salmon available to consumers of conservation concern such as eagles

45 (Levi et al. 2015), bears (Deacy et al. 2016), and trout (Bentley et al. 2012).Consumers are easily 
46 satiated by even modest densities of spawning salmon, so the duration of spawning activity is

47 likely just as important to consumers as the abundance of salmon (Jeschke 2007). Despite the

48 importance of small tributary salmon escapement to salmon management, ecosystem function,

49 and salmon conservation, existing methods of monitoring salmon abundance do not perform well

50 at these sites, given high financial costs, investment of time, and the potential to alter salmon

51 behavior.

52

53

54

55

56

57

58

59

60

61

62

63

64

65

66

67

68

Traditionally, anadromous salmonids (Oncorhynchus spp.) moving into large rivers or streams have been counted by observers stationed at fish weirs, fences, and observation towers, or by use of sonar stations (Table 1; Cousens et al. 1982, Johnson et al. 2007). These methods can produce reliable estimates; however, high labor and equipment costs make them too expensive for simultaneously monitoring many streams. To fill this gap, researchers have experimented with systems that record video of passing salmon using either under or above water cameras (Hatch et al. 1994, Davies et al. 2007, Van Alen 2008). These video weir methods have three key advantages: 1) footage can be reviewed long after the data are collected, allowing a small crew to monitor several runs simultaneously; 2) periods with high salmon abundance can be counted more accurately by reducing playback speed; and 3) fewer site visits reduce impacts on wildlife caused by human presence. Although these benefits have made video enumeration an increasingly popular method for counting salmonids, reviewing large amounts of video is required. The resulting personnel costs make video weir methods impractical for many applications. A method is needed for collecting escapement data that produces reliable estimates without thousands of hours of video review or frequent site visits. Furthermore, some enumeration methods (i.e. weirs) can obstruct natural movements of salmon and other fishes. This may not be a problem on main-stem rivers if salmon tend to move consistently upstream, 
69 however, it is problematic in small streams where diel movements into and out of streams are

70

71

72 common (Bentley et al. 2014).

In addition to total escapement, studies focused on consumer responses to availability of salmon need to know the number of living salmon in streams (hereafter in stream abundance) across time. In stream abundance across time represents foraging opportunities better than gross escapement when consumers are swamped by a pulsed resource, which is often the case for consumers of spawning salmon (Armstrong and Schindler 2011). Typically, in stream abundance data are collected using ground (Quinn et al. 2001) or aerial surveys (Neilson and Geen 1981) which are repeated several times during a salmon run. Ground surveys work well on streams that are easy to access, small enough to survey in a reasonable amount of time, and where disturbing wildlife is not a concern. Aerial surveys may work well for less accessible sites if visibility from the plane is not impeded by riparian vegetation or complex channel geomorphology. Moreover, because salmon abundance in streams tends to change rapidly, these methods only work well when the survey frequency is high. Furthermore, to collect reliable data using aerial surveys, researchers need to correct for differences among observers (Bue et al. 1998). Here, we present an alternative method for estimating the number of living salmon in a stream through the full duration of the run. The approach combines daily estimates of salmon passage, collected using our time-lapse camera system, with a model of spawning salmon mortality.

Our system requires service only every 14 days, detects salmon $24 \mathrm{hrs}$. /day, is inexpensive to implement, and produces escapement estimates with confidence intervals. This system works on rivers and streams up to $\sim 15 \mathrm{~m}$ wide and $\sim 1 \mathrm{~m}$ deep. In addition, we present a method for estimating in stream salmon abundance, data which are important for studies focused 
92 on the response of wildlife consumers to salmon runs and nutrient subsidies. To demonstrate

93 proof of concept, we present results from two small streams with very high densities of salmon.

94 Methods

95 Approach

96 To harness the advantages of remote camera systems without time-consuming video

97 enumeration, we utilized a "double sampling" scheme, which is often used when a variable of

98 interest is costly to measure, but an auxiliary variable is more easily measured and has a

99 predictable relationship to the variable of interest (Cochran 1977). The cheaper variable can be

100 measured for all of the sample units while the expensive variable is measured on a subsample of

101 units in order to model the relationship between the variables. Here, our variable of interest is

102 the number of salmon that pass into and out of a stream each hour, which we can accurately

103 quantify with an above-water video camera. The related auxiliary variable is the number of

104 salmon detected in time-lapse images each hour. The total time required to review footage is

105 low relative to video-only approaches because we only have to enumerate salmon in a subset of

106 the hour long sample units. We determined the salmon passage for the remaining hours by

107 modelling the relationship between the subsample of hourly video counts and photo counts and

108 then using the model to predict salmon passage across the entire salmon run.

109

110

111

112

113

\section{Study Streams}

We developed this method on two streams used by spawning sockeye salmon: Meadow and Southeast Creeks (Fig. 1a) in southwest Kodiak Island, Alaska. Meadow Creek is a second order tributary to Karluk Lake. It has a mean width of $4.50 \mathrm{~m}$ and depth of $13 \mathrm{~cm}$ in the lower $0.8 \mathrm{~km}$ used by spawning salmon. Southeast Creek is a first order tributary to Red Lake that 
114 flows out of a small spring pond. It has a mean width of $3.90 \mathrm{~m}$ and depth of $9.1 \mathrm{~cm}$ in the lower

$1152.7 \mathrm{~km}$ used by spawning salmon. Salmon enter these streams annually to spawn and

116 bidirectional movement and pre-spawn mortality is common owing to a large number of brown

117 bears that prey on the salmon.

118 Time lapse camera system

119 To record time lapse images of passing salmon, we used a Reconyx ${ }^{\circledR}$ Hyperfire PC800

120 camera, programmed to take 3 photos in rapid succession $(<1 \mathrm{sec}$. between frames) each minute,

$12124 \mathrm{hrs}$./day. Each three frame burst allowed us to detect the number and direction of travel (up

122 or downstream) of salmon passing the camera. We suspended the time lapse camera above the

123 stream using steel electrical conduit attached to a steel Big Game ${ }^{\circledR}$ Pursuit tripod tree stand

124 positioned adjacent to the stream, approximately $50 \mathrm{~m}$ upstream of the lake (Fig. $1 \mathrm{~b})$. We

125 attached the camera to the conduit with a Camlockbox ${ }^{\circledR}$ ball mount which allowed us to easily

126 aim the camera. To light the streambed at night we secured an LTS® IR50 850nm infrared (IR)

127 light to the tripod platform. Although visible light would have worked well, we used IR light to

128 avoid changing the behavior of salmon and/or their predators with visible light. The Reconyx

129 camera and infrared light were powered by an 80 amp-hour deep-cycle battery charged by a

$130100 \mathrm{~W}$ solar panel secured to the south side of the tower.

To record video, we secured a video camera to the top of the tower. The video footage was stored by a Digital Video Recorder (DVR) set to record D1 resolution, 30 frames per second video from $12 \mathrm{pm}-8 \mathrm{pm}$, the periods with the best quality video (good light) and the majority of

134 salmon movement activity. The video camera and DVR were powered by its own battery/solar 135 power system, identical to the one powering the Reconyx camera and IR light. To make passing 
136 salmon easier to see, we secured $50.8 \mathrm{~cm} \mathrm{X} 76.2 \mathrm{~cm}$ white High Density Polyethylene (HDPE)

137 contrast panels to the bottom of the stream below the cameras by attaching them to a heavy chain 138 (Alaska Department of Fish and Game Permit \# FH-14-II-0076). The HDPE panels are buoyant 139 in water and the chain prevents the panels from floating off of the streambed. Using stainless 140 steel carabineers, we attached the chain to T-posts which we pounded into the margins of the 141 streambed. To prevent salmon from swimming under the panels, we pinned the chain to the 142 stream bed using several steel stakes.

We visited each camera system every two weeks from early June through early

144 September to switch out data cards and remove algae and debris from the contrast panels. Back

145 at our field station, we separately counted the number of salmon moving up and downstream past

146 the contrast panels during each three-photo burst. We only counted a salmon as passing if it

147 moved at least $1 / 2$ the length of the panels; we did not count stationary fish. Finally, we summed

148 upstream and downstream counts separately for each hour of the monitoring season. To ensure

149 consistent counting technique, each stream was counted by the same person for the entire season.

Modelling salmon escapement (abundance)

We used a model-based double sampling approach to estimate salmon escapement. We modelled the relationship between video salmon counts and photo salmon counts for a nonrandom subsample of hours, and then used this model to predict salmon passage for the entire season. This is different from the "sampling-design approach" more commonly used to double sample (Cochran 1977). If we had used the sampling-design approach, we would have counted

156 the salmon passing in a simple random subsample of video hours, and then calculated the total 157 escapement by multiplying the time lapse salmon count by the ratio of video counts to photo 
158 counts in the subsample. However, the sampling design-based approach has two requirements 159 which are difficult to satisfy. First, to be random, every hour of the salmon run must be available 160 for sampling, meaning that video must be recorded throughout the entire run. A single day of 161 missed video (due to a power outage, insects sitting on the lens, etc.) could significantly bias the 162 resulting abundance estimates if the outage occurred on a day with relatively few or many 163 passing salmon. Second, the video must be high enough quality to assume $100 \%$ salmon 164 detection. This requirement can be difficult to meet because of glare and poor night-time video 165 quality. Rather than attempt to design a system that meets these strict requirements, we used a 166 model-based approach, where we model the relationship between video counts and time lapse counts (Stephens et al. 2012). This framework allows us to select our sample of videoenumerated hours non-randomly; our estimate of abundance is unbiased as long as the model is correctly specified (Hansen et al. 1983, Gregoire 1998).

We selected 70 hours that spanned the full range of hourly time-lapse salmon counts,

171 from the hours with many salmon swimming downstream to hours with strong upstream

172 movement. Also, we selected hours where we were confident of nearly $100 \%$ detection, 173 excluding hours with bad glare or poor lighting. In total, we watched 70 hours of video for each 174 stream, however, because we considered up and downstream salmon movement independently, 175 this gave us a sub-sample of 140 values for each stream (70 upstream counts and 70 downstream 176 counts).

177 Next, we modelled video counts as a function of time-lapse photo counts for the 178 subsample. All statistical analyses were conducted using the statistical program R 3.1.3 (R 179 Development Core Team, 2015). We compared four different models for each stream: first and 180 second order linear regressions and first and second order segmented or "split-point" linear 
181 regressions (package "segmented") (Table 2). The segmented regression allows the slope to

182 differ across ranges of the predictor variable. This makes sense for salmon swimming in a

183 stream; salmon swimming upstream (positive values) might move slower, and thus have a

184 greater chance of being detected in a time-lapse burst. In contrast, salmon swimming

185 downstream (negative values) might move faster and have a lower likelihood of detection. To

186 address this possibility, we including segmented regression models with the split-point (slope

187 inflection point) constrained to zero. To assess relative model fit, we compared Akaike's

188 Information Criterion values ( $\mathrm{AIC}_{\mathrm{c}}$; Akaike 1974). To validate models and test for over-fitting,

189 we performed leave one out cross validation (LOOCV; Kohavi 1995), and used the resulting

190 predictions to calculate the precision (mean squared error, MSE) and accuracy (the percent

191 difference between the predicted and actual escapement of the 70 hours for which we watched

192 video). Based on these metrics, we selected a top model for each stream.

193

Using the best model for each stream, we predicted the salmon passage for all of the

194 hours of the monitoring period. The sum of these predictions is the estimated escapement.

195 Because we did not use random sampling to select our modelling subsample, it is inappropriate

196 to use the model variance to calculate confidence intervals for total escapement. Instead, we

197 bootstrapped our subsample (R package "boot") with replacement (140 values to match our

198 original subsample), refit our model using the top model structure, and re-predicted the total

199 escapement (Efron and Tibshirani 2003). We repeated this 10,000 times and used the 2.5 and

20097.5 percentile values as upper and lower 95\% confidence intervals of total escapement. 
203 (upstream moving salmon minus downstream moving salmon), and applied mortality estimates

204 from the literature. Carlson et al. (2007) investigated the relationship between stream

205 width/depth and stream life (number of days from salmon stream entry to death) on a range of

206 tributaries to Nerka and Aleknagik Lakes, Alaska which are morphologically similar to our focal

207 streams. The three main sources of mortality for spawning sockeye salmon were senescent

208 death, predation (mostly by bears), and stranding. They found that salmon spawning in

209 wider/deeper streams tended to have longer stream lives. The authors' explanation was that

210 salmon in shallow/narrow streams experienced higher predation rates which selects for more

211 rapid reproductive cycles and consequently earlier deaths. Because of this interaction between

212 stream morphology and salmon stream life, it is probably inappropriate to use a single estimate

213 of stream life across streams with varying morphology. We used the results of Carlson et al.

214 (2007; Table 1) to create a model of stream life as a function of stream morphology.

Assuming salmon in our streams were equally likely to die by stranding, predation, and senescence as they were in the Carlson study, we calculated a weighted average of the mean

217 stream life (weighted by the number of salmon dying by each mechanism) for each of the

218 Carlson et al. (2007; Table 1) streams. We then used this weighted average stream life as the response variable and stream width and depth as predictor variables in a simple linear regression model. Because stream depth and width were strongly correlated $(\mathrm{r}=0.90)$, including both variables in the model resulted in collinearity. We thus selected between depth-only and width-

222 only models by comparing $\mathrm{AIC}_{\mathrm{c}}$ scores. We then used the top model to predict the mean stream 223 life of sockeye salmon in Meadow and Southeast Creek, using field measurements of stream 224 morphology measured in 2014 as predictors. There was a strong positive correlation between the 
225 mean and pooled standard deviation (Hedges 1981) of stream life in the Carlson data $(\mathrm{r}=0.95$,

$226 \mathrm{p}=0.004)$; therefore, rather than model the standard deviation (SD) of stream life separately from

227 the mean, we assumed stream life $\mathrm{SD}$ was proportional to the mean $(\mathrm{SD}=0.499 *$ mean stream

228 life).

To calculate in stream abundance each day, we summed the number of salmon that entered on that day with the predicted number of surviving salmon from the previous days:

$$
\text { Living Salmon On Day } x=\sum_{t=1}^{N} P_{x}+P_{x-t} S_{t}
$$

where $P_{x}$ is the number of salmon that passed into the stream on day $x, P_{x-t}$ is the number of salmon that passed into the stream $t$ days before day $x, S_{t}$ is the proportion of those salmon surviving to day $x$, and $t$ is an index of days. The values of $S_{t}$ are from the cumulative distribution function of survival which we modelled above. $\mathrm{N}$ is the number of days it takes for survival $\left(S_{t}\right)$ to reach zero, which varies based on the survival model (it will be larger on deeper streams where stream life is greater).

To understand the sensitivity of in stream abundance models to changes in stream life estimates, we calculated in stream abundance for each stream across a range of stream life values. We then used percent change in maximum abundance to assess the impact of changing stream life. Because the amount of time consumers have access to salmon is at least as important as peak abundance, we also calculated the duration of the salmon run, defined as the number of days where abundance was at least ten percent of the maximum in stream estimate from the un-

244 altered model. This (admittedly arbitrary) ten percent threshold was an attempt to set a lower limit on the salmon density below which benefits to consumers decline. 


\section{Results}

247 Salmon Escapement

Of the suite of models relating video counts to time lapse counts for Meadow Creek, the top model was the segmented first order model (Table 2, Fig. 2). It had the lowest $\mathrm{AIC}_{\mathrm{c}}$

250 (1534.3), best precision (MSE=3556), and best accuracy $(+3.0 \%)$. The segmented models likely explained more variation than the unsegmented models because salmon had different detection rates while swimming upstream versus downstream (salmon swim slower against the current), in the relatively steep gradient of Meadow Creek. Using the top model, the predicted escapement for Meadow Creek was 30,509 \pm 9,494 (95\% confidence intervals). $\mathrm{AIC}_{\mathrm{c}}(1732.2)$, best precision $(\mathrm{MSE}=14167)$, and best accuracy $(+3.1 \%)$. In contrast to Meadow

257 Creek, the segmented model only explained slightly more variation than the first order model, but required an additional parameter. This suggests salmon in Southeast Creek have a similar

259 detection rate whether they are swimming up or downstream, which is likely because Southeast 260 Creek has a relatively flat gradient and low velocity. The total escapement for Southeast Creek was $65,355 \pm 4,305$ (95\% confidence intervals). For Southeast Creek, the escapement estimates were not very sensitive to the model selected (maximum difference of only 4.4\%) (Fig. 3). This contrasts with Meadow, where the difference between the highest and lowest estimate was 38\%.

The model with depth as a predictor $\left(\mathrm{AIC}_{\mathrm{c}}=27.5\right)$ explained more variation than the width model $\left(\mathrm{AIC}_{\mathrm{c}}=31.9\right)$, so we used this model to predict mean stream life for our two streams. Meadow Creek had a predicted mean stream life of 7.1 days $(\mathrm{SE}=3.5)$ while Southeast 
268 Creek (which is shallower), had a predicted stream life of 5.9 days ( $\mathrm{SE}=3.0)$. Using these values,

269 we found the predicted salmon abundance over time in each stream were quite different;

270 abundance peaked at just over 11,000 sockeye on July $11^{\text {th }}$ in Meadow Creek and the run was

271 finished around August 16 $6^{\text {th }}$ (Fig. 4). In contrast, Southeast Creek had two distinct peaks in

272 abundance: the first on July $21^{\text {st }}$ with just over 15,000 sockeye and the second peaking at 4,645

273 on August $29^{\text {th }}$. Thus, although the total escapement in Southeast Creek was more than double

274 that of Meadow Creek, the peak salmon abundance was only $29 \%$ higher in Southeast.

In general, the in stream abundance models were quite sensitive to changes in stream life

276

277

278

279

280

281

282

283 estimates. Increasing mean stream life in Meadow Creek by 2 days, from 7.1 to 9.1 days, increased the estimated maximum abundance by $14 \%$ (Fig. 5). The effect was even greater on Southeast Creek, with a $22 \%$ increase in abundance from a 2 day increase in mean stream life. Increasing the standard deviation had the opposite effect: a 1 day increase in SD of stream life decreased the maximum abundance by 5\% and 3\% on Meadow and Southeast Creeks, respectively. The sensitivity of salmon run duration (defined as the number of days with at least $10 \%$ of the maximum salmon abundance), to changes in mean and SD of stream life was less clear. On Meadow Creek, increasing mean stream life by 2 days increased the salmon run duration by 2 days (from 40 to 42 days) and increasing stream life SD by 1 day resulted in no measurable increase in salmon run duration. In contrast, the same changes on Southeast Creek resulted in a 5 day and 2 day increase in salmon run duration for changes to the mean and SD of stream life, respectively. This difference is likely because Southeast Creek has two distinct peaks in salmon abundance, and a 2 day increase in stream life is a larger proportional change compared to Meadow creek.

\section{Discussion}


291 Researchers and managers increasingly acknowledge the important role of small salmon

292 populations in generating stable returns for commercial fisheries and for supporting wildlife of

293 high economic and commercial value (Schindler et al. 2010, Beacham et al. 2014). Many

294 existing salmon monitoring tools were designed primarily for large streams and rivers and are

295 ineffective or too expensive for monitoring the salmon populations that use small streams for

296 spawning. The time-lapse salmon counting system presented here proved to be a low-cost, time-

297 efficient, and accurate method for counting salmon in streams less than $15 \mathrm{~m}$ wide. This method

298 only required bi-weekly site visits, which is ideal for remotely monitored sites and studies

299 involving the response of wildlife to spawning salmon. These benefits will allow managers and

300 researchers to quantify salmon in streams where it was previously too difficult or expensive. In

301 addition, we presented a method for estimating the number of living salmon in a stream across

302 the run, data which are particularly important for consumer-resource studies.

(number of days a salmon survives following spawning stream entry) based upon data collected in the Wood River system, Alaska (Carlson et al. 2007). These data are specific to the sites and years where they were collected; differences in water level, intensity of predation, and salmon abundance are all likely to change these values. For these reasons, future users of the method we demonstrated here should estimate stream life in their own systems, rather than relying on the model developed using the Carlson et al. (2007) data. This is particularly important because a sensitivity analysis showed our in stream salmon estimates were quite sensitive to changes in estimated stream life (Fig. 5); a two day increase in stream life increased the estimated maximum abundance by $14 \%$ on Meadow Creek and $22 \%$ on Southeast Creek. 
314 relationship between time lapse and video counts (Hansen et al. 1983). This is critical given the

315 large differences in abundance estimates resulting from small differences in model structure or

316 fit (Table 2, Fig. 4). It is important to consider multiple model shapes; different stream

317 morphologies or salmon species may produce different salmon run patterns. For example, steep

318 streams are likely to produce models with different slopes for salmon swimming upstream and

319 downstream. The segmented model structure can account for this pattern, and thus should

320 always be included in the candidate model set. Also, a polynomial model might be appropriate

321 for streams that experience high densities of spawners. In general, a polynomial model is needed

322 if time-lapse detection of passing salmon changes with salmon run intensity. For example, as

323 salmon reach high densities, they may not be able to move upstream very quickly because of

324 crowding. This could result in relatively higher detection at high run intensities. In this case, a

325 polynomial model would likely model the relationship better than a first order model.

326 Regardless of the model shape, it is important that users use standard model diagnostics and

327 good sense to fit the best model possible.

We have learned several important lessons from testing this method on different streams

329 and different sites within streams. First, this counting system is most accurate and requires the

330 least effort when located where flow is rapid but the water surface is smooth. The rapid flow

331 prevents salmon from loitering above the contrast panels (which can introduce noise into the

332 time-lapse counts), while the smooth water surface makes it easy to see passing salmon. Second,

333 this system works best in shallow streams. Deep streams $(>1 \mathrm{~m})$ were problematic because

334 salmon were more likely to swim at different depths, which caused their outlines to overlap and

335 made counting more difficult. It was also more difficult to light deep streams at night. We 
336 found that our infrared lights did not light passing salmon adequately if streams were more than

337 one meter deep. Using conventional flood lights (visible light) solves this problem; however, it

338 negates the advantages of using IR lights, which is invisible to humans, fishes, and most wildlife.

339 Third, it is important to orient the camera away from the sun (northward in the northern

340 hemisphere), because otherwise the surface of the water reflects glare towards the camera.

341 Although this new method increases the breadth of sites that can be monitored, it has

342 some limitations. As with other methods, the turbidity associated with high flow events can

343 make seeing passing salmon difficult or impossible. Fortunately, these events tend to be brief in

344 the small streams for which we designed this system. Also, it can be difficult to distinguish

345 among species if a site has multiple species migrating at the same time. Finally, this system can

346 only monitor streams up to $15 \mathrm{~m}$ wide. Beyond this width, counting accuracy is likely to

347 decrease as the salmon in the images become more distant. One potential solution is to use two

348 camera towers on opposite banks, each viewing one half of the stream.

Using this system, it can be difficult to accurately model the relationship between timelapse counts and salmon passage if escapement is less than two or three thousand salmon. This

351 is because at low escapement, hourly time-lapse counts tend to vary little, regardless of the

352 relative intensity of the run. This makes it difficult to effectively model the relationship between 353 time-lapse photo counts and video counts. One solution to this problem is to increase observer

354 effort by either increasing the length of the sampling unit (e.g. from one to two hours) or by

355 increasing the sampling frequency (e.g. 3-photo burst every 30 seconds). This would increase

356 the contrast between weak and strong runs, but also increase the time required to review photos

357 and/or video. Another solution is to use a model from a stream with similar features (width, 358 depth, velocity, etc.), although we know from the data presented here that models can differ 
359 greatly among streams (Table 2). For example, if we had used the Southeast Creek model to

360 estimate Meadow Creek escapement, we would have overestimated by $89 \%$ compared to the

361 Meadow Creek top model.

In general, salmon researchers should strive to minimize their impact on natural salmon behavior. In small streams such as those monitored here, spawning salmon tend to move up and downstream frequently (Fig. 4, top), a behavior that may be a strategy for avoiding predators (Bentley et al. 2014). Salmon monitoring methods such as weirs have the potential to limit these movements. This could allow predators such as bears to catch salmon more easily, which could decrease salmon spawning success rates and alter trophic interactions with salmon consumers. A key strength of the method presented here is that it allows salmon to move freely and allows natural interactions with salmon consumers.

As with many resources used by wildlife, salmon availability is very patchy in space and time (Armstrong and Schindler 2011). This presents a challenge for researchers and managers interested in using sampling to estimate their abundance; the more patchy or pulsed the salmon run, the less accurate a random sampling method will be without large amounts of effort. Here,

374 we overcame this challenge by using a model-based design instead of a random sampling-based design. This allowed us to relax the demands on our camera system; rather than requiring complete video coverage, we merely needed hours of video that represented the full range of

377 salmon run intensities. Given the ubiquity of patchy (in space) or pulsed (in time) resource 378 availability, we suspect that this approach to double sampling could be employed in a variety of 379 natural resources applications. 
381 habitats that can be realistically monitored. Due to their low cost and relative portability, these 382 systems would be ideal for monitoring salmon populations of conservation concern. For 383 example, they could produce baseline and ongoing data on the abundance of salmon spawning 384 downstream of mines or other resource development projects. Compared to existing methods, 385 our solution is less expensive, less time consuming, and less detrimental to salmon and the 386 wildlife that use them. The data produced can help improve our understanding of how 387 population dynamics at small scales creates stability at the watershed scale. 


\section{Acknowledgements}

This work evolved from the early video enumeration efforts of Mat Sorum. His experimentation with remote video systems greatly accelerated the development of the methods presented here.

We appreciate the staff at the Kodiak National Wildlife Refuge and Flathead Lake Biological

Station for their committed support and assistance for this project. We thank Caroline Cheung, and volunteer field technicians Barbara Svoboda, Alex May, Bill Dunker, Tim Melham, Tyler Tran, Marie Jamison, Louisa Pless, Francesca Cannizzo, Isaac Kelsey, Mark Melham, Jane Murawski, Prescott Weldon, Shelby Flemming, Andy Orlando, and Kristina Hsu for their hard work in the field and lab. We thank pilots Kurt Rees and Kevin VanHatten for their skilled flying.

\section{References}

Akaike, H. 1974. A new look at the statistical model identification. IEEE Transactions on Automatic Control 19:716-723.

Van Alen, B. W. 2008. Kook Lake sockeye salmon stock assessment, 2005-2007. Anchorage, Alaska.

Anderson, T., and B. McDonald. 1978. A portable weir for counting migrating fishes in rivers.

Armstrong, J. B., and D. E. Schindler. 2011. Excess digestive capacity in predators reflects a life of feast and famine. Nature 476:84-7.

Beacham, T. D., S. Cox-Rogers, C. MacConnachie, B. McIntosh, and C. G. Wallace. 2014. Population Structure and Run Timing of Sockeye Salmon in the Skeena River, British Columbia. North American Journal of Fisheries Management 34:335-348.

Bentley, K., D. Schindler, and J. Armstrong. 2012. Foraging and growth responses of streamdwelling fishes to inter-annual variation in a pulsed resource subsidy. Ecosphere 3.

Bentley, K. T., D. E. Schindler, T. J. Cline, J. B. Armstrong, D. Macias, L. R. Ciepiela, and R. Hilborn. 2014. Predator avoidance during reproduction: diel movements by spawning sockeye salmon between stream and lake habitats. The Journal of animal ecology:14781489.

Bue, B. G., S. M. Fried, S. Sharr, D. G. Sharp, J. A. Wilcock, and H. J. Geiger. 1998. Estimating salmon escapement using area-under-the curve, aerial observer efficiency, and stream-life estimates: The Prince William Sound pink salmon example. NPAFC Bulletin 1:240-250. 
419

420

421

422

423

424

425

426

427

428

429

430

431

432

433

434

435

436

437

438

439

440

441

442

443

444

445

446

447

448

449

450

451

452

453

454

455

456

Carlson, S. M., R. Hilborn, A. P. Hendry, and T. P. Quinn. 2007. Predation by bears drives senescence in natural populations of salmon. PloS one 2:e1286.

Cochran, W. G. 1977. Sampling Techniques.

Cousens, N. B. F., G. A. Thomas, C. G. Swann, and M. C. Healey. 1982. A Review of Salmon Escapement Estimation Techniques. Canadian Technical Report of Fisheries and Aquatic Sciences.

Davies, T. D., D. G. Kehler, and K. R. Meade. 2007. Retrospective sampling strategies using video recordings to estimate fish passage at fishways. North American Journal of Fisheries Management 27:992-1003.

Deacy, W., W. Leacock, J. B. Armstrong, and J. A. Stanford. 2016. Kodiak brown bears surf the salmon red wave: direct evidence from GPS collared individuals. Ecology 97:1091-1098.

Efron, B., and R. J. Tibshirani. 2003. Introduction to the Bootstrap. Chapman and Hall.

Gregoire, T. G. 1998. Design-based and model-based inference in survey sampling: appreciating the difference. Canadian Journal of Forest Research 28:1429-1447.

Grifantini, M. C., R. Teubert, R. Aschbacher, and M. Mitchell. 2011. Video Weir Technology Pilot Project Final Project Report. Anderson, CA.

Hansen, M. H., W. G. Madow, and B. J. Tepping. 1983. An evaluation of model-dependent and probability-sampling inferences in sample surveys. Journal of the American Statistical Association 78:776-793.

Hatch, D. R., M. Schwartzberg, and P. R. Mundy. 1994. Estimation of Pacific Salmon Escapement with a Time-Lapse Video Recording Technique. North American Journal of Fisheries Management 14:626-635.

Hedges, L. V. 1981. Distributional theory for Glass's estimator of effect size and related estimators. Journal of Educational Statistics 6:107-128.

Hilborn, R., T. P. Quinn, D. E. Schindler, and D. E. Rogers. 2003. Biocomplexity and fisheries sustainability. Proceedings of the National Academy of Sciences of the United States of America 100:6564-8.

Holmes, J., G. Cronkite, H. Enzenhofer, and T. Mulligan. 2006. Accuracy and precision of fishcount data from a "dual-frequency identification sonar" (DIDSON) imaging system. ICES Journal of Marine Science 63:543-555.

Jeschke, J. M. 2007. When carnivores are "full and lazy". Oecologia 152:357-64.

Johnson, D. H., Shrier, B. M., O’Neal, J. S., Knutzen, J. A., Augerot, X., O’Neil, T. A., \& Pearsons, T. N. (2007). Salmonid field protocols handbook: techniques for assessing status and trends in salmon and trout populations. American Fisheries Society.

Kohavi, R. 1995. A Study of Cross-Validation and Bootstrap for Accuracy Estimation and Model Selection. International Joint Conference on Artificial Intelligence 14:1137-1143.

Levi, T., R. E. Wheat, J. M. Allen, and C. C. Wilmers. 2015. Differential use of salmon by vertebrate consumers: implications for conservation. PeerJ 3:e1157. 
457

458

459

460

461

462

463

464

465

466

467

468

469

470

471

472

473

474

475

476

Maxwell, S. L., and N. E. Gove. 2007. Assessing a dual-frequency identification sonars' fishcounting accuracy, precision, and turbid river range capability. The Journal of the Acoustical Society of America 122:3364-3377.

Neilson, J. D., and G. H. Geen. 1981. Enumeration of Spawning Salmon From Spawner Residence Time and Aerial Counts. Transactions of the American Fisheries Society 110:554-556.

Quinn, T. P., L. Wetzel, S. Bishop, K. Overberg, and D. E. Rogers. 2001. Influence of breeding habitat on bear predation and age at maturity and sexual dimorphism of sockeye salmon populations. Canadian Journal of Zoology 79:1782-1793.

R Development Core Team. 2015. R: A language and environment for statistical computing. Vienna: R Foundation for Statistical Computing. Available at http://www.r-project.org

Schindler, D., J. Armstrong, K. Bentley, K. Jankowski, P. Lisi, and L. Payne. 2013. Riding the crimson tide: mobile terrestrial consumers track phenological variation in spawning of an anadromous fish. Biology Letters 9:2-6.

Schindler, D. E., R. Hilborn, B. Chasco, C. P. Boatright, T. P. Quinn, L. a Rogers, and M. S. Webster. 2010. Population diversity and the portfolio effect in an exploited species. Nature 465:609-12.

Stephens, P. R., M. O. Kimberley, P. N. Beets, T. S. H. Paul, N. Searles, A. Bell, C. Brack, and J. Broadley. 2012. Airborne scanning LiDAR in a double sampling forest carbon inventory. Remote Sensing of Environment 117:348-357 
Table $\mathbf{1}$ (on next page)

Comparison of salmon enumeration methods. 


\begin{tabular}{|c|c|c|c|c|c|}
\hline & Method & $\begin{array}{l}\text { Typical } \\
\text { sites }\end{array}$ & Advantages & Disadvantages & $\begin{array}{l}\text { Refere } \\
\text { nces }\end{array}$ \\
\hline \multirow{2}{*}{ 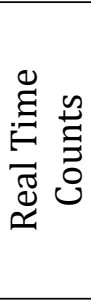 } & Weir & $\begin{array}{l}\text { Large clear } \\
\text { rivers/ } \\
\text { streams }\end{array}$ & $\begin{array}{l}\text { Easy sampling of age, sex, length, } \\
\text { genetics }\end{array}$ & $\begin{array}{l}\text { Expensive } \\
\text { (equipment/personnel) } \\
\text {; May hinder natural } \\
\text { fish movements }\end{array}$ & $\begin{array}{l}\text { Anderson } \\
\text { and } \\
\text { McDonal } \\
\text { d } 1978 \\
\end{array}$ \\
\hline & $\begin{array}{l}\text { Observat- } \\
\text { ion Tower }\end{array}$ & $\begin{array}{l}\text { first to fifth } \\
\text { order clear } \\
\text { streams / } \\
\text { rivers }\end{array}$ & Does not hinder fish passage & $\begin{array}{l}\text { Expensive (personnel); } \\
\text { turbulence or bad light } \\
\text { can make counts } \\
\text { difficult }\end{array}$ & $\begin{array}{l}\text { Cousens } \\
\text { et al. } \\
1982\end{array}$ \\
\hline \multirow{4}{*}{ 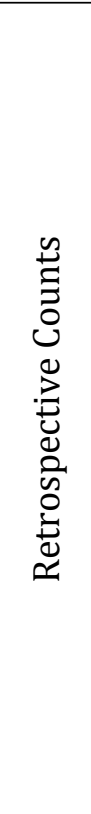 } & Sonar & $\begin{array}{l}\text { Large clear or } \\
\text { opaque rivers }\end{array}$ & $\begin{array}{l}\text { Not affected by turbulence; Records of } \\
\text { run can be saved and reviewed; } \\
\text { Playback can be slowed and counts } \\
\text { repeated for QA/QC; Does not obstruct } \\
\text { fish passage }\end{array}$ & $\begin{array}{l}\text { Expensive } \\
\text { (equipment/personnel) } \\
\text {; Lengthy footage } \\
\text { review; Accuracy } \\
\text { suffers at highest } \\
\text { densities }\end{array}$ & $\begin{array}{l}\text { Holmes } \\
\text { et al. } \\
2006 ; \\
\text { Maxwell } \\
\text { and Gove } \\
2007\end{array}$ \\
\hline & $\begin{array}{l}\text { Video net } \\
\text { weir }\end{array}$ & $\begin{array}{l}\text { medium to } \\
\text { small rivers } \\
\text { and streams }\end{array}$ & $\begin{array}{l}\text { Records of run can be saved and } \\
\text { reviewed; Playback can be slowed and } \\
\text { counts repeated for QA/QC; Does not } \\
\text { obstruct fish passage }\end{array}$ & $\begin{array}{l}\text { Expensive(equipment/ } \\
\text { personnel); Lengthy } \\
\text { footage review; May } \\
\text { hinder natural } \\
\text { movements of fish; Nets } \\
\text { can catch debris }\end{array}$ & $\begin{array}{l}\text { Van Alen } \\
2008, \\
\text { Grifantini } \\
\text { et al. } \\
2011\end{array}$ \\
\hline & $\begin{array}{l}\text { Above } \\
\text { water } \\
\text { video }\end{array}$ & $\begin{array}{l}\text { Medium to } \\
\text { small clear } \\
\text { streams }\end{array}$ & $\begin{array}{l}\text { Records of run can be saved and } \\
\text { reviewed; Playback can be slowed and } \\
\text { counts repeated for QA/QC; Does not } \\
\text { obstruct fish passage }\end{array}$ & $\begin{array}{l}\text { Expensive; Time } \\
\text { consuming footage } \\
\text { review }\end{array}$ & $\begin{array}{l}\text { Hatch et } \\
\text { al. } 1994\end{array}$ \\
\hline & $\begin{array}{l}\text { Time-lapse } \\
\text { double } \\
\text { sampling }\end{array}$ & $\begin{array}{l}\text { Medium to } \\
\text { small clear } \\
\text { streams }\end{array}$ & $\begin{array}{l}\text { Inexpensive; Can be left unattended for } \\
14 \text { days; Records of run can be saved } \\
\text { and reviewed; Playback can be slowed } \\
\text { and counts repeated for QA/QC; Does } \\
\text { not obstruct fish passage; decreased } \\
\text { impacts on wildlife }\end{array}$ & $\begin{array}{l}\text { Limited to smaller } \\
\text { streams }(<15 \mathrm{~m})\end{array}$ & $\begin{array}{l}\text { Current } \\
\text { study }\end{array}$ \\
\hline
\end{tabular}




\section{Table 2 (on next page)}

Details of salmon passage models.

Model descriptions, escapement estimates and model validation metrics. AICc is Aikaike's Information Criterion adjusted for small sample size (Akaike 1974). 95\% confidence intervals on escapement were calculated using bootstrap resampling methods. Accuracy is the percent difference between the leave-one-out cross-validation predicted escapement and the actual escapement for the 70 hours where escapement was counted using video recording. Precision is the mean squared error (MSE). The top model for each stream is in italics. 


\begin{tabular}{|c|c|c|c|c|c|c|c|}
\hline & $\begin{array}{l}\text { Model } \\
\text { Name }\end{array}$ & Model of Sockeye Passage & $\mathbf{k}$ & AlCc & $\begin{array}{c}\text { Escapement } \\
\text { estimate } \\
( \pm 95 \% \mathrm{Cl})\end{array}$ & Accuracy & Precision \\
\hline \multirow{4}{*}{ 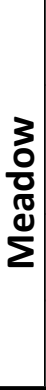 } & $\begin{array}{l}\text { segmented } \\
\text { first order }\end{array}$ & $\begin{array}{c}\text { pass }=(x>0) * 15.242+ \\
(x<0) * 18.920)\end{array}$ & 2 & 1534.30 & $\begin{array}{c}30,509 \\
( \pm 9,494)\end{array}$ & $+3.0 \%$ & 3556 \\
\hline & $\begin{array}{l}\text { segmented } \\
\text { polynomial }\end{array}$ & $\begin{array}{l}\text { pass }=(x>0) * 16.096+(x>0)^{2 *} \\
-0.0206+(x<0)^{*} 18.454+(x<0)^{2 *} \\
-0.0206\end{array}$ & 3 & 1535.02 & $\begin{array}{c}30,064 \\
( \pm 14,211)\end{array}$ & $+10.1 \%$ & 3557 \\
\hline & first order & pass $=x * 16.1441$ & 1 & 1551.56 & $\begin{array}{c}41,539 \\
( \pm 3,692)\end{array}$ & $+37.5 \%$ & 3917 \\
\hline & polynomial & $\begin{array}{c}\text { pass }=x * 17.3137+ \\
\left(x^{2} *-0.04552\right)\end{array}$ & 2 & 1535.94 & $\begin{array}{c}31,830 \\
( \pm 11,628) \\
\end{array}$ & $+24.4 \%$ & 3591 \\
\hline \multirow{4}{*}{ 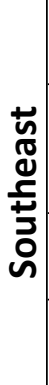 } & $\begin{array}{l}\text { segmented } \\
\text { first order }\end{array}$ & $\begin{array}{c}\text { pass }=(x>0) * 22.78+ \\
(x<0) * 22.18)\end{array}$ & 2 & 1733.43 & $\begin{array}{c}68,253 \\
( \pm 15,759) \\
\end{array}$ & $+7.2 \%$ & 14932 \\
\hline & $\begin{array}{l}\text { segmented } \\
\text { polynomial }\end{array}$ & $\begin{array}{c}\text { pass }=(x>0) * 22.555+(x>0)^{2 *} 0.0045+ \\
(x<0) * 22.653+(x<0)^{2} * \\
-0.0045\end{array}$ & 3 & 1735.26 & $\begin{array}{c}66,303 \\
( \pm 23,052)\end{array}$ & $+5.7 \%$ & 15569 \\
\hline & first order & pass $=x * 22.505$ & 1 & 1732.17 & $\begin{array}{c}65,355 \\
( \pm 4,305) \\
\end{array}$ & $+3.1 \%$ & 14167 \\
\hline & polynomial & $\begin{array}{c}\text { pass }=x * 22.589+ \\
\left.x^{2} *-0.0040\right)\end{array}$ & 2 & 1733.44 & $\begin{array}{c}66,610 \\
( \pm 8,045)\end{array}$ & $+6.2 \%$ & 14669 \\
\hline
\end{tabular}

1 


\section{1}

Map and pictures of counting system

A) Map of southwest Kodiak Island, Alaska showing the locations of streams where salmon were counted using time-lapse double sampling. B) Salmon counting system including foldable steel tower holding a time-lapse camera (box at top), video camera, and solar panels. The tower is surrounded by an electric fence to prevent equipment disruption by bears. White high density polyethylene (HDPE) plastic panels were placed on the stream bed to improve sightability of sockeye salmon (Oncorhynchus nerka). C) An image of two sockeye salmon passing across the contrast panels, with the video camera in the foreground.
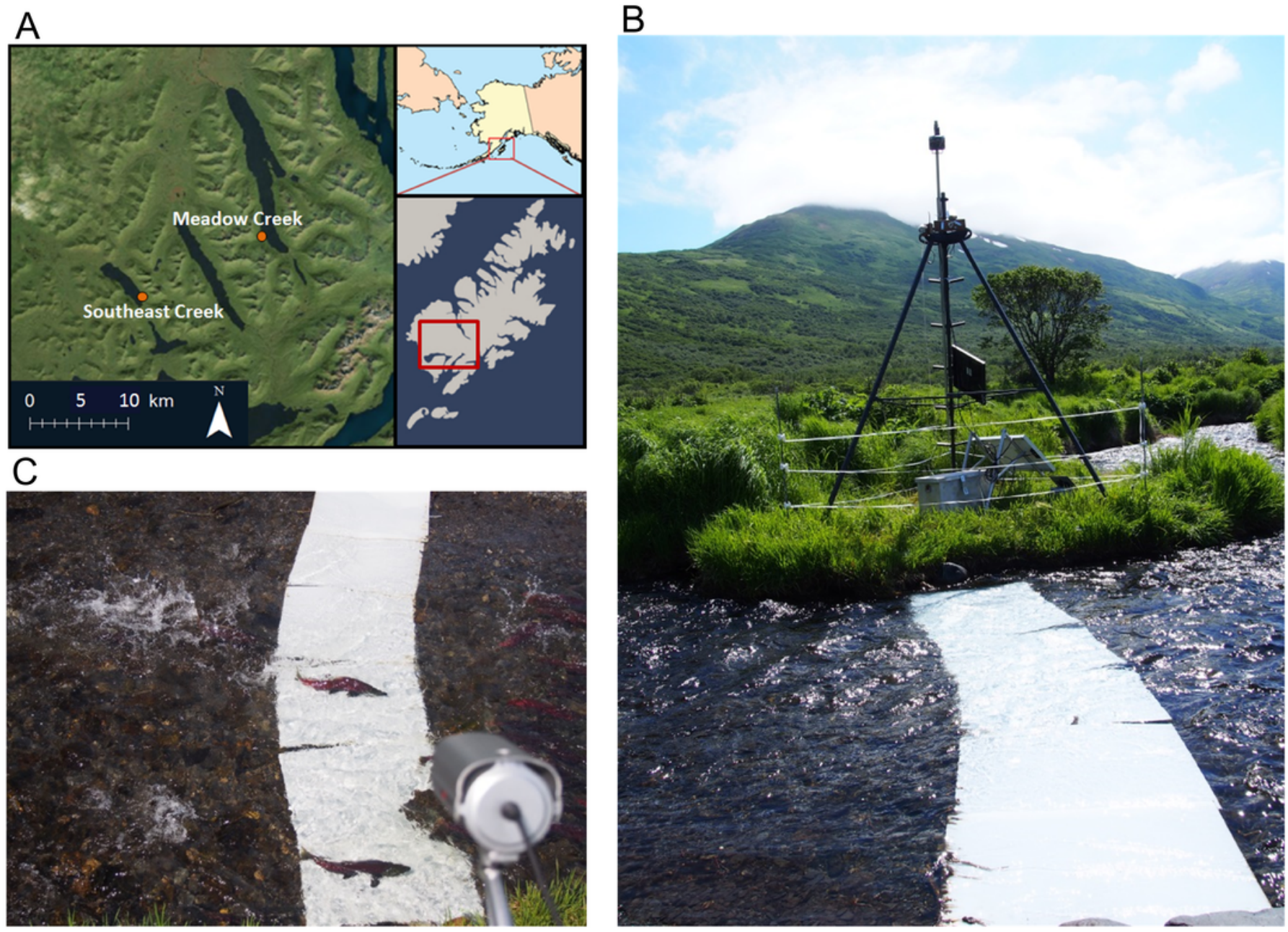
2

Relationship between hourly time-lapse and video counts of salmon passage for two streams in southwest Kodiak Island, Alaska

The lines show the top model for each stream, selected using Akaike's Information Criterion adjusted for small sample size (AIC $C_{c}$ )(Akaike 1974): a segmented first order relationship for Meadow Creek, and a simple first order linear relationship for Southeast Creek. The segmented model (Meadow) has a different slope above and below the origin, which is indicated by crossed vertical and horizontal dashed lines. 


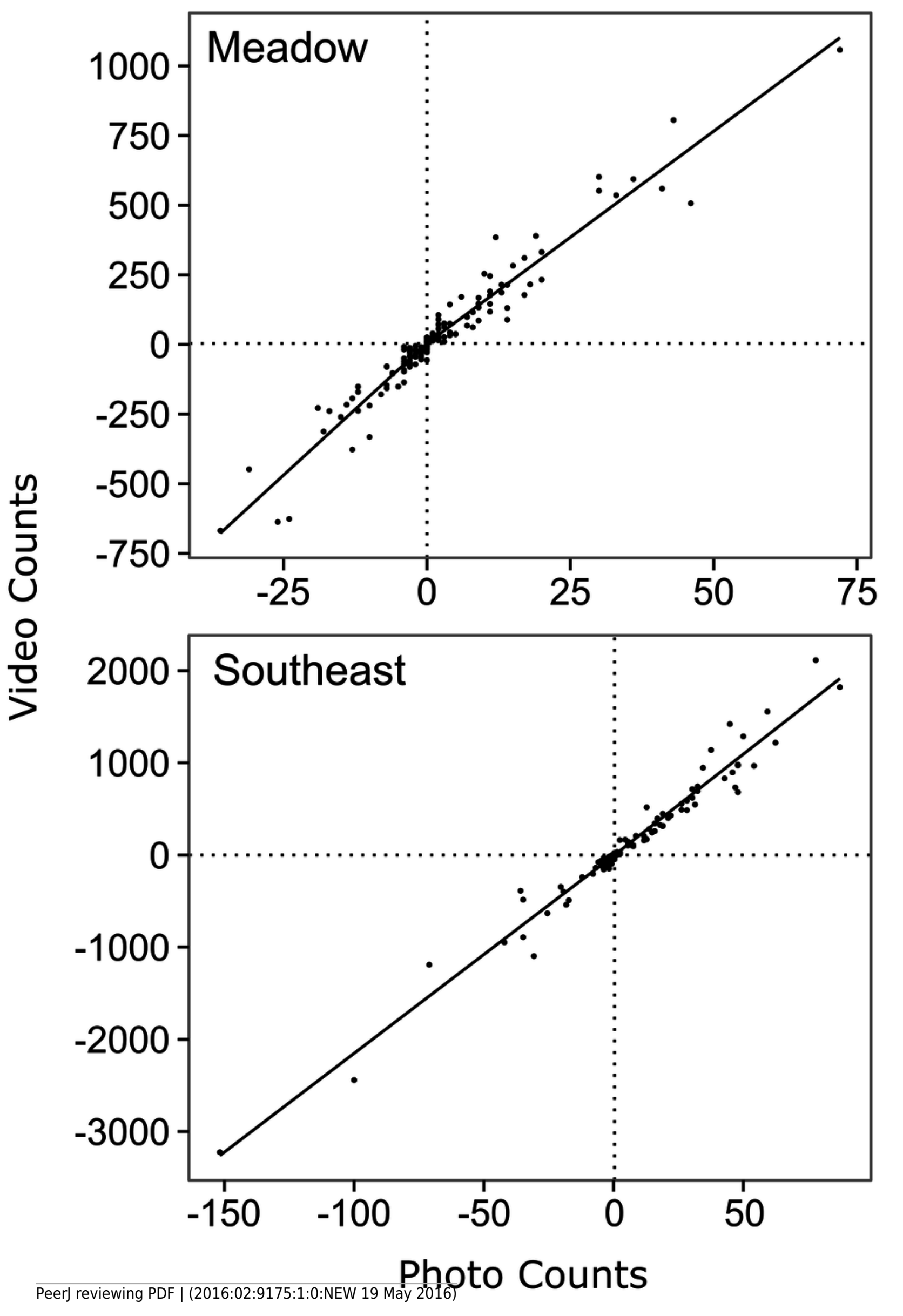


3

In-stream salmon abundance calculated using four different models

Comparison of estimates of the number of living sockeye salmon in two streams (Meadow Creek at top, Southeast Creek at bottom) derived using four different models (model details in Table 1). 


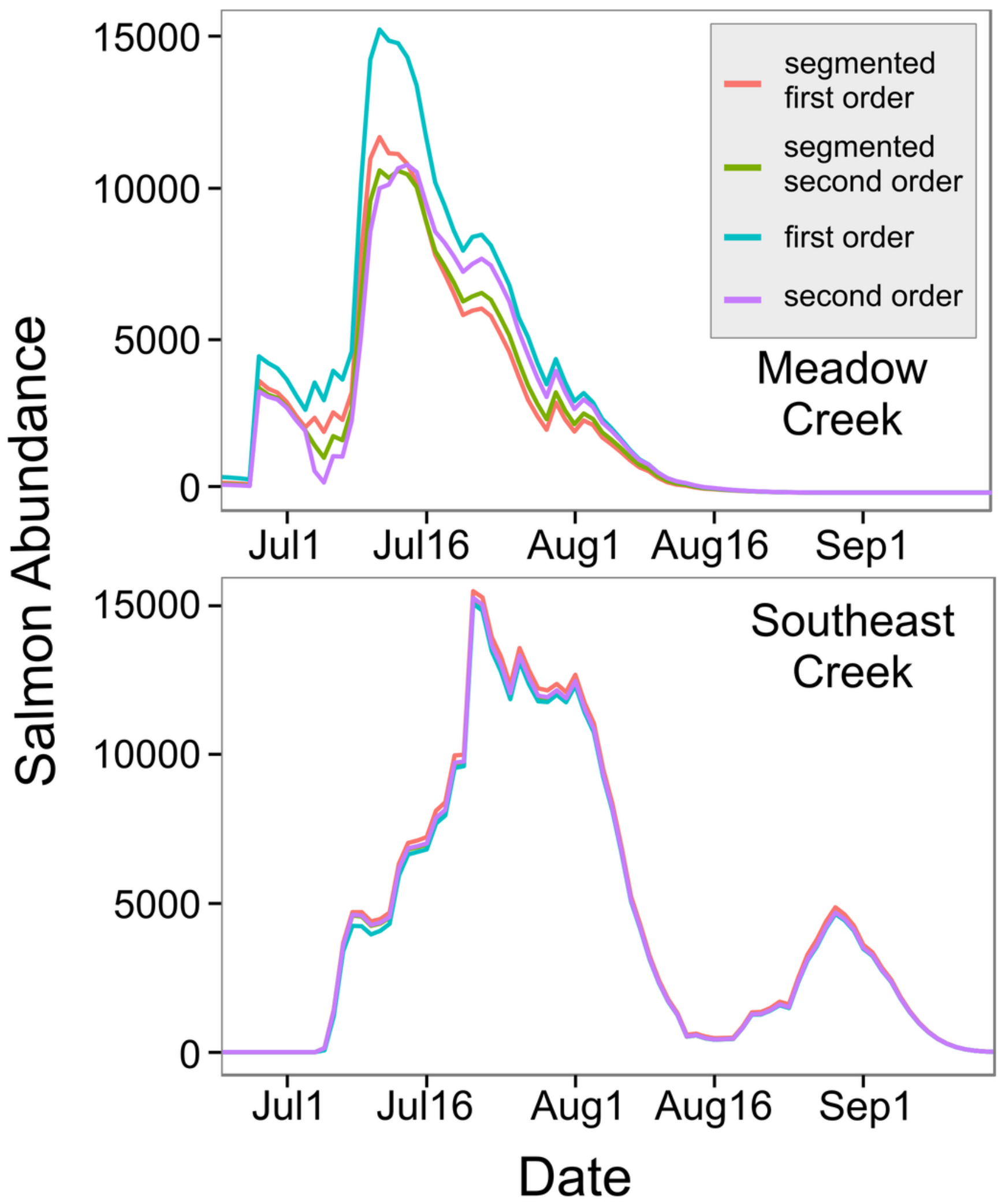


4

Estimated salmon passage, escapement, and in-stream abundance.

Estimated hourly sockeye salmon passage (top), estimated cumulative passage (middle), and estimated in-stream salmon abundance (bottom) in Meadow and Southeast Creeks. In the salmon passage plots (top row), positive numbers indicate salmon moving into the stream from the downstream lake, while negative numbers indicate salmon leaving the stream and entering the lake.
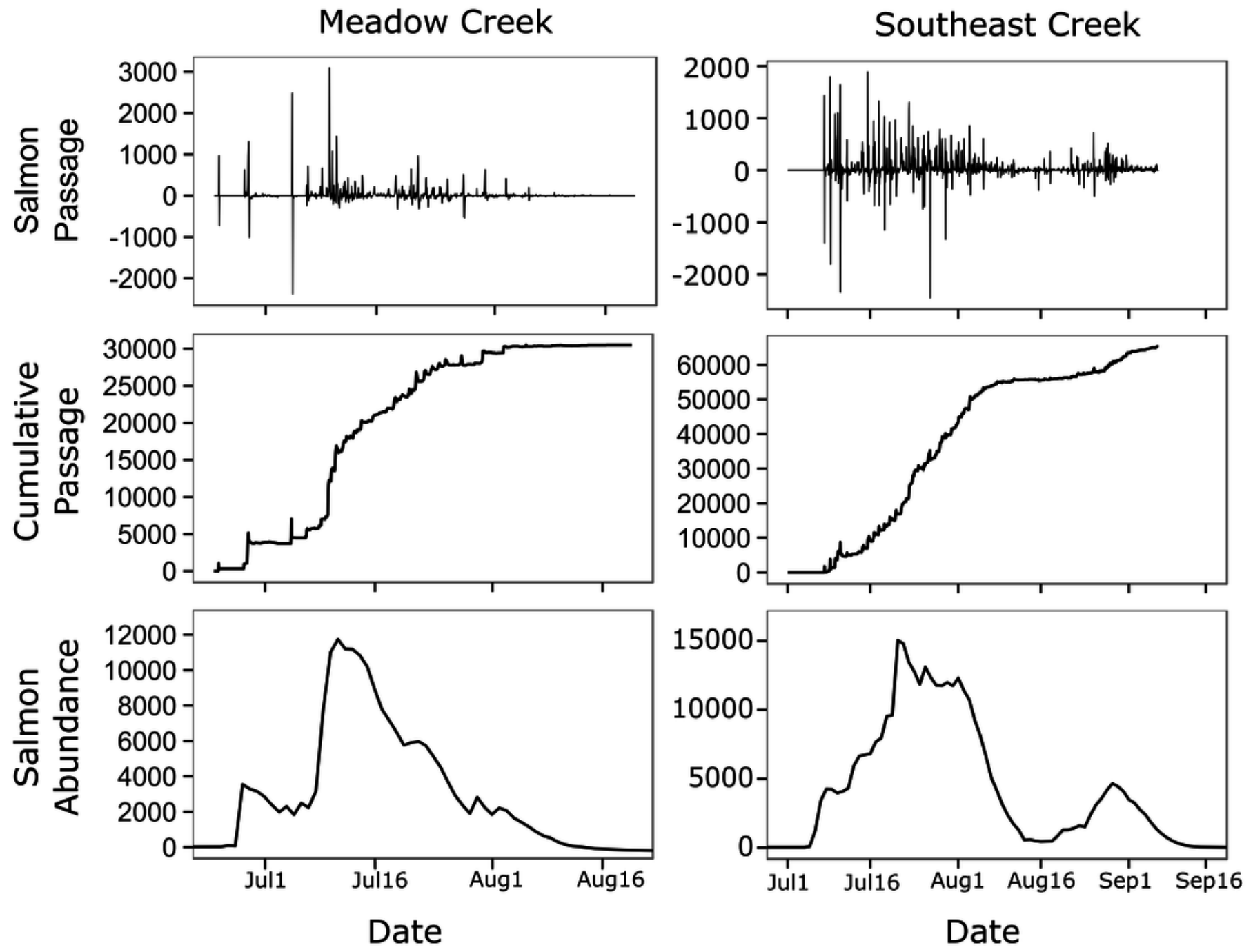


\section{5}

Sensitivity of in-stream salmon abundance estimates to changes in stream life.

Effect of altering mean and standard deviation (SD) of sockeye salmon survival (in days) on the estimated in-stream salmon abundance in Meadow and Southeast Creeks. In the top row the mean was manipulated, while the SD was altered in the bottom row of plots. In all plots, the unaltered model is shown in black.
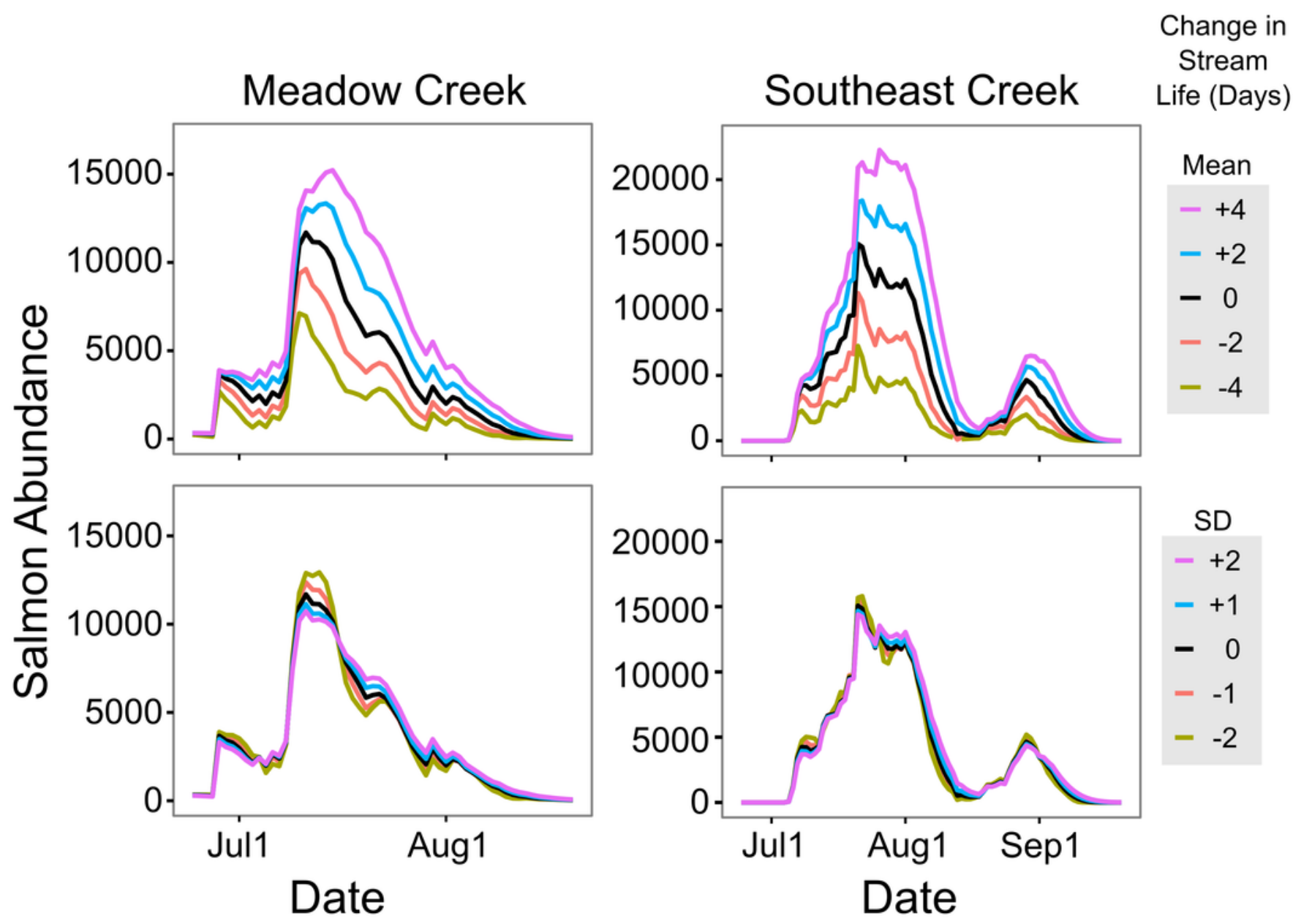